\title{
Determination of Pregnane-17,21-diol-20-ones in Human Urine
}

\author{
BY J. K. NORYMBERSKI AND ANN RIONDEL \\ Unit for Endocrine Chemistry, Department of Zoology, University of Sheffield, Sheffield S10 2TN, U.K., and \\ Laboratoire de Physiopathologie Clinique, Université de Genève, Geneva, Switzerland
}

(Received 8 June 1970)

\begin{abstract}
Treatment of urine or of a urine extract with periodate followed by treatment of the acidic oxidation products with sodium bismuthate gave a mixture of neutral end products consisting only or predominantly of 17-oxoandrostanes derived from the corresponding urinary pregnane-17,21-diol-20-ones. The mixture of end products was resolved by gas-liquid or paper chromatography. The latter technique was used to determine cortisol secretion rates and the results were found to be in reasonable agreement with those obtained by a double-isotope method. Gas-liquidchromatographic characterization of steroidal 4-en-3-ones is described.
\end{abstract}

A general approach to the analysis of steroids has been outlined in which the analytical sample is submitted to a sequence of chemical transformations and fractionations so selected that a small group of closely related products can be separated from all or most other constituents of the sample and that each product derives from a single precursor (Norymberski, 1966). Specific analytical schemes have been suggested, among them one for the determination of pregnane-17,21-diol-20-ones (partial formula I, Scheme 1). Compounds of this class are oxidized by periodate to 17-hydroxyaetianic acids (II) and by sodium bismuthate to 17-oxoandrostanes (III) (Brooks \& Norymberski, 1953). Consequently, were an analytical sample containing 17,21-diol-20-ones (I) to be treated with periodate, and the acidic fraction of the reaction mixture separated and treated with sodium bismuthate, the resultant neutral fraction should contain 17 -ones (III) derived exclusively from the diolones (I). Other constituents of the fraction could be ketones or aldehydes derived from compounds containing a dihydroxyacetone fragment or from $\alpha$-hydroxy acids not removed before oxidation with periodate. In applying the proposed scheme to the analysis of human urine advantage was taken of the fact that urinary steroids conjugated with glucuronic acid are converted by periodate into formates and the latter are readily hydrolysed by alkali (Few, 1961).

\section{MATERIALS AND METHODS}

All solvents and reagents were of analytical grade. Acetylations, reductions with $\mathrm{NaBH}_{4}$ and oxidations with $\mathrm{CrO}_{3}$ were carried out as described by Bush (1961). G.l.c. was carried out on $1 \%$ SE-30/Gas-Chrom $Q$ in 2 mlong columns with a Varian Aerograph model 204 or with a Carlo Erba Fractovap GI series 450 instrument, both equipped with flame-ionization detectors and solidinjection systems. Radioactivity was counted in a Packard Tri-Carb model 3002 scintillation counter. A Packard model 7200 scanner was used for the detection of radioactivity on paper chromatograms.

Sequential oxidation. The sample (cortisol or urine extract), in ethanol $(0.5 \mathrm{ml})$, was mixed with oxalic acid $(10 \mathrm{mg})$ and aqueous $\mathrm{NaIO}_{4}(2.0 \mathrm{ml} ; 2 \%, \mathrm{w} / \mathrm{v})$ and the mixture was then adjusted to $\mathrm{pH} 6.5-7.0$ with $\mathrm{M}-\mathrm{NaOH}$<smiles>CC1CC[C@@](O)(C(=O)CO)C1C</smiles>

(I)

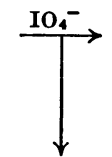

First neutral fraction (discarded)<smiles>CC1CCC(O)(C(=O)O)C1(C)C</smiles>

(II)

\section{First} acidic fraction

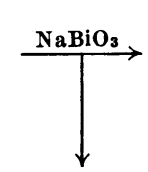

Second acidic fraction (discarded)<smiles>CC1CCC(=O)C1(C)C</smiles>

Second neutral fraction

Scheme 1. Sequential oxidation of cortisol. 
( 5 drops) and left for $2 \mathrm{~h}$ at room temperature. Aqueous $\mathrm{Na}_{2} \mathrm{SO}_{3}(1.0 \mathrm{ml} ; 10 \%, \mathrm{w} / \mathrm{v})$ was added and the mixture then adjusted to $\mathrm{pH} 1.0-1.5$ with $\mathrm{M}_{-} \mathrm{H}_{2} \mathrm{SO}_{4}$ (approx. $0.5 \mathrm{ml})$ and extracted with chloroform $(2 \times 5.0 \mathrm{ml})$. The acidic products were extracted from the organic phase with $\mathrm{M}-\mathrm{NaOH}(2 \times 2.0 \mathrm{ml})$. The extract was treated with acetic acid $(2.0 \mathrm{ml})$, oxalic acid $(10 \mathrm{mg})$ and sodium bismuthate $(100 \mathrm{mg})$. The mixture was shaken for $0.5 \mathrm{~h}$ at room temperature, an aqueous solution of sodium metabisulphite $(0.75 \mathrm{ml} ; 10 \%, w / v)$ then added and the mixture was extracted with chloroform $(2 \times 5.0 \mathrm{ml})$. The extract was washed with $\mathrm{M}-\mathrm{NaOH}(3 \times 3.0 \mathrm{ml})$ and then with water $(2 \times 1.0 \mathrm{ml})$, dried over anhydrous $\mathrm{Na}_{2} \mathrm{SO}_{4}$ and evaporated to dryness.

Determination of urinary unconjugated 17,21-diol-20. ones. Urine (up to $1250 \mathrm{ml}$ ) was extracted with chloroform $(4 \times 0.25$ vol. $)$; the extract was washed with $\mathrm{M}-\mathrm{NaOH}$ $(2 \times 0.05$ vol. $)$, then with water $(2 \times 0.05$ vol. $)$ and evaporated. The residue was submitted to the sequential oxidation procedure described above. The second neutral fraction was dissolved in light petroleum (b.p. $40-60^{\circ} \mathrm{C}$; $2.0 \mathrm{ml})$, the solution was extracted with water $(2 \times 2.0 \mathrm{ml})$, the aqueous phase extracted with carbon tetrachloride $(3 \times 4.0 \mathrm{ml})$ and the extract evaporated to dryness. Suitable portions of the residue were taken for g.l.c. and for micro-chemical reactions.

Determination of urinary glucosiduronic acids of 17,21diol-20-ones. Urine (usually $5.0 \mathrm{ml}$ ) was first extracted with chloroform $(4 \times 0.25 \mathrm{vol}$. $)$ and then treated with aqueous $\mathrm{NaIO}_{4}(10 \%, \mathrm{w} / \mathrm{v} ; 0.4 \mathrm{ml} / \mathrm{ml}$ of urine). The following operations were carried out as described above except that the amounts of solvents and reagents were adjusted as necessary and that the partition step was omitted.

Cortisol secretion rates. $\left[4-{ }^{14} \mathrm{C}\right]$ Cortisol $(0.5-1.0 \mu \mathrm{Ci}$; specific radioactivity $29.2 \mathrm{mCi} / \mathrm{mmol}$ ) was given to four healthy adults (subjects $1-4$ in Table 2 ) and to a woman with Conn's syndrome (subject 5). Urine specimens were collected over the next $24 \mathrm{~h}$. A sample $(20 \mathrm{ml})$ of each specimen was treated as for the determination of glucosiduronic acids of 17,21-diol-20-ones except that preextraction with chloroform was omitted. The second neutral fraction was chromatographed on paper in cyclohexane-benzene--methanol-water $(5: 2: 5: 1$, by vol.) with over-running for $24 \mathrm{~h}$. Radioactive areas corresponding to 11-oxoacetiocholanolone (3 $\alpha$-hydroxy-5 $\beta$-androstane11,17-dione), $11 \beta$-hydroxyaetiocholanolone $\quad(3 \alpha, 11 \beta$ dihydroxy-5 $\beta$-androstan-17-one) and $11 \beta$-hydroxyandrosterone $(3 \alpha, 11 \beta$-dihydroxy-5 $\alpha$-androstan-17-one) were eluted. Portions of each eluate were taken for the counting of radioactivity, for measurement by the Zimmermann reaction (with the appropriate authentic materials as standards) and for g.l.c.

Secretion rates were also determined by a doubleisotope derivative method involving the following operations: (1) hydrolysis with $\beta$-glucuronidase followed by extraction with dichloromethane; (2) paper chromatography in benzene-methanol-water $(4: 2: 1$, by vol.) followed by elution of the radioactive fractions corresponding to tetrahydrocortisone and tetrahydrocortisol+ allotetrahydrocortisol; (3) acetylation with $\left[{ }^{3} \mathrm{H}\right]$ acetic anhydride $(0.5 \mathrm{mCi} / \mathrm{mmol})$; (4) paper chromatography first in 1,3,5-trimethylbenzene-methanol-water $(3: 2: 1$, by vol.) then in cyclohexane-benzene-methanol-water
(5:2:5:1, by vol.); (5) partial hydrolysis with methanolic $0.4 \% \mathrm{KHCO}_{3} ;(6)$ paper chromatography first in cyclohexane-benzene-methanol-water $(2: 2: 2: 1$, by vol. $)$ then in 2,2,4-trimethylpentane-2-methylpropan-2-ol-methanol-water (4:3:4:2, by vol.). In all instances the last chromatographic step did not significantly alter the ${ }^{3} \mathrm{H} /{ }^{14} \mathrm{C}$ ratio of the eluted material.

\section{RESULTS}

Preliminary experiments. After the sequential oxidation of $\left[4{ }^{14} \mathrm{C}\right]$ cortisol, $1.5 \pm 0.1 \%$ of the radioactivity was found in the first neutral fraction and $89 \pm 4 \%$ in the second neutral fraction (means \pm s.D. from six replicate determinations) (Scheme 1). When $\left[4-{ }^{14} \mathrm{C}\right]$ cortisol was added to a neutralchloroform extract of pooled urine and the same procedure followed, the corresponding values were $1.6 \pm 0.3$ and $89 \pm 4 \%$ (five replicates) respectively. In every instance but one, paper chromatography of the second neutral fraction showed the presence of only one radioactive product with the mobility of $11 \beta$-hydroxy-4-androstene-3,17-dione. The exception was when a more mobile by-product was found accounting for about $10 \%$ of the radioactivity. This was eluted from the paper and chromatographed in the system 2,2,4-trimethylpentane2-methylpropan-2-ol-methanol-water $(4: 3: 4: 2$, by vol.) : the $R_{F}$ value $(0.30)$ in this system differed from that of 4-androstene-3,11,17-trione, a possible by-product of the oxidation of cortisol. It is considered unlikely that the unidentified by-product was formed during treatment with periodate or sodium bismuthate, since all oxidations were performed under identical conditions. A more likely explanation is the decomposition of $\left[{ }^{14} \mathrm{C}\right]-$ cortisol.

Urinary unconjugated 17,21-diol-20-ones. The second neutral fraction from the sequential oxidation of a chloroform extract of pooled normal urine was purified by a simple partition step (see the Materials and Methods section). This was necessary to remove the impurities introduced in the processing of relatively large volumes of urine or water. To assess the losses of $11 \beta$-hydroxyandrost-4-ene-3,17dione (derived from cortisol), the authentic ${ }^{14} \mathrm{C}$ labelled compound was partitioned in the same manner; the recovery was $95 \%$ or more. The recoveries of other 17-ones were not determined; they may be expected to be very low for 11-deoxy17-ones.

G.l.c. of the purified material gave, except for peaks due to very volatile components, only three peaks (A, B and $\mathrm{C}$ in Fig. 1) with the retention times of 11-oxoaetiocholanolone, 4-androstene3,11,17-trione $+11 \beta$-hydroxyaetiocholanolone and $11 \beta$-hydroxy-4-androstene-3,17-dione respectively. Oxidation with chromic anhydride of another sample 
of that fraction followed by g.l.c. gave two peaks with the retention times of $5 \beta$-androstane-3,11,17trione and 4-androstene-3,11,17-trionerespectively. However, the fact that the former constituent was more abundant than the latter suggested that peak $B$ of the original sample was due to both 4-androstene-3,11,17-trione and $11 \beta$-hydroxyaetiocholanolone.

For further characterization of the mixture of the 17-ones advantage was taken of the dehydration of 4-en-3-ols on a g.l.c. column (Chamberlain \& Thomas, 1963), presumably to a mixture of the corresponding 2,4- and 3,5-dienes. Table 1 shows that the sequence reduction-g.l.c. or reductionacetylation-g.l.c. allows one to distinguish 4-en-3ones from other unsaturated 3-ones as well as from

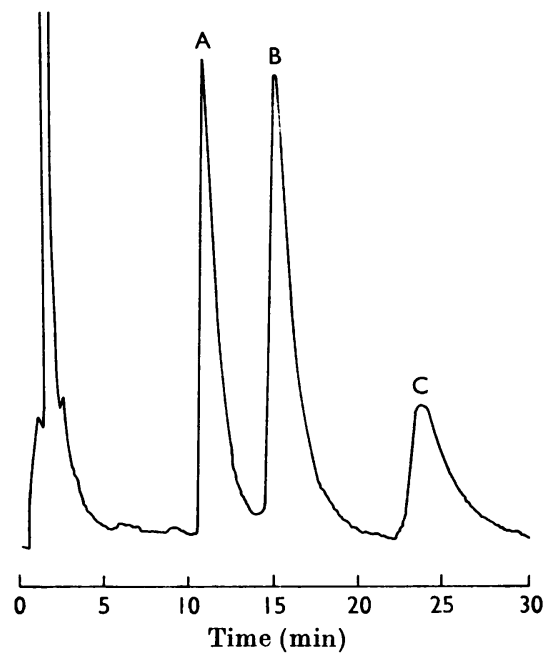

Fig. 1. G.l.c. on $1 \%$ SE-30 at $195^{\circ} \mathrm{C}$ with a Varian model 204 Aerograph. The sample derives from the unconjugated fraction and corresponds to $22 \mathrm{ml}$ of pooled normal female urine. For explanation of peaks A, B and C, see the text. all saturated ketones. When the investigated mixture was reduced with borohydride and then acetylated, g.l.c. gave the characteristic double peak expected from androstenetrione and $11 \beta$. hydroandrostenedione and another peak with the retention time of $3 \alpha, 17 \beta$-diacetoxy-5 $\beta$-androstan$11 \beta$-ol expected from 11 -oxo- and from $11 \beta$-hydroxyaetiocholanolone.

Dr C. J. W. Brooks and Mr B. S. Middleditch (Department of Chemistry, University of Glasgow, Glasgow, U.K.) submitted the same mixture to g.l.c. on a OV-1 column and obtained mass spectra of the emerging fractions. The spectrum of the first fraction was in very good agreement with that of authentic 11-oxoaetiocholanolone. That of the second fraction strongly indicated the presence of androstenetrione as the major component and of $11 \beta$-hydroxyaetiocholanolone as the minor component. The last fraction gave a weak spectrum, but correlation with $11 \beta$-hydroxyandrostenedione was satisfactory. It is concluded that the four 17ketones were the principal constituents of the sample obtained by sequential oxidation of the urine extract and that consequently cortisol, cortisone, tetrahydrocortisol and tetrahydrocortisone were the principal 11-oxygenated 17,21-diol20-ones in that extract.

Urinary glucosiduronic acids of 17,21-diol-20-ones. The glucosiduronic acids of steroidal 17,21-diol-20. ones were determined in urine specimens from ten subjects. Except for very volatile components and slight impurities introduced during the analytical procedure (see Fig. 2c), no g.l.c. fractions were detected other than those attributable to aetiocholanolone, androsterone and their 11-oxo and $11 \beta$. hydroxy derivatives. Fig. 2(a) shows the g.l.c. resolution of the second neutral fraction obtained from the urine of a healthy man and Fig. 2(b) that of a mixture of the authentic compounds. G.l.c.mass-spectroscopic analysis was inconclusive because of the similarity between the spectra of 5epimers and the possibility of cross-contamination

Table 1. G.l.c. characterization of some $\alpha, \beta$-unsaturated oxo steroids

(A), Column 1 at $185^{\circ} \mathrm{C}$; (B), column 2 at $185^{\circ} \mathrm{C}$; (C), column 2 at $198^{\circ} \mathrm{C}$; (D), column 3 at $217^{\circ} \mathrm{C}$. All columns consisted of $1 \% \mathrm{SE}-30$.

\section{Parent compound}

Testosterone

$11 \beta$-Hydroxy-4-androstene-3,17-dione

Progesterone

4-Cholesten-3-one

$5 \alpha$-Androst-1-ene-3,17-dione

$17 \beta$-Hydroxy-1,4-androstadien-3-one

4,6-Pregnadiene-3,20-dione
$t_{R}$ relative to parent compound

\begin{tabular}{llc}
\hline $\begin{array}{c}\text { After reduction } \\
\text { with } \mathrm{NaBH}_{4}\end{array}$ & $\begin{array}{c}\text { After reduction- } \\
\text { acetylation }\end{array}$ \\
$0.33 / 0.38$ & (B) & $0.47 / 0.55$ (C) \\
$0.30 / 0.35$ & (A) & \\
$0.33 / 0.38$ & (A) & $0.48 / 0.58$ (C) \\
$0.33 / 0.41$ & (D) & \\
$0.90 / 0.95$ & (A) & $2.18 / 2.33$ (C) \\
$0.33 / 0.35 / 0.49$ (B) & \\
0.28 & (A) & 0.51 (C)
\end{tabular}




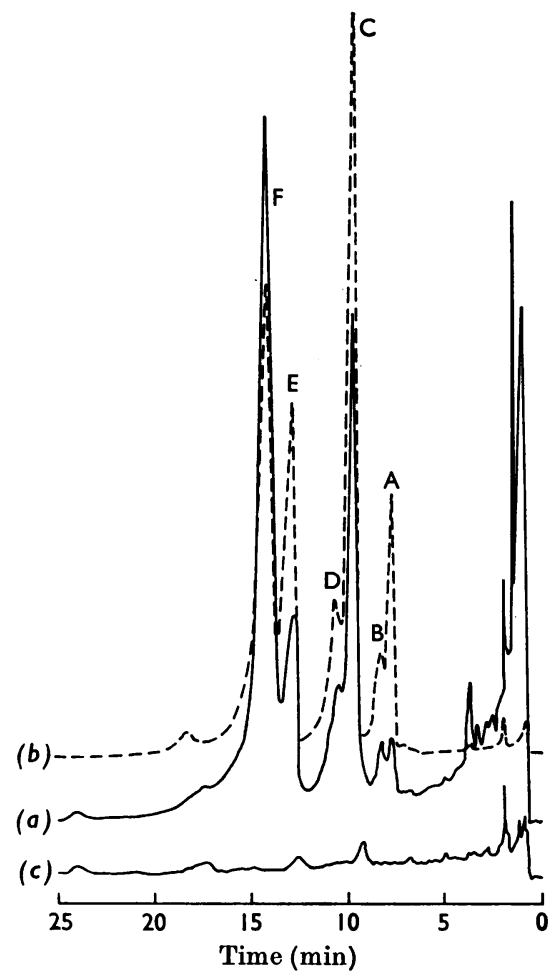

Fig. 2. G.l.c. on $1 \% \mathrm{SE}-30$ at $210^{\circ} \mathrm{C}$ with a Carlo Erba Fractovap GI Series 450. (a) Sample corresponding to $0.2 \mathrm{ml}$ of urine from a healthy man; $(b)$ mixture of aetiocholanolone $(0.20 \mu \mathrm{g} ; \mathrm{A})$, androsterone $(0.08 \mu \mathrm{g} ; \mathrm{B})$, 11 -oxoaetiocholanolone $(0.64 \mu \mathrm{g} ; \mathrm{C}), 11$-oxoandrosterone $(0.17 \mu \mathrm{g} ; \mathrm{D}), 11 \beta$-hydroxyaetiocholanolone $(0.50 \mu \mathrm{g} ; \mathrm{E})$ and $11 \beta$-hydroxyandrosterone $(0.80 \mu \mathrm{g} ; \mathrm{F})$, emerging from the column in that order; $(c)$ sample corresponding to $0.2 \mathrm{ml}$ of water treated as the urine specimen; all determinations were at the same attenuation $(10 \times 4)$.

between the members of each of the three epimeric pairs. However, the mass numbers of the molecular ions were correct and no inconsistency was found with the assignations of structure based on chemical and g.l.c. evidence. Experimentally induced and pathological changes of adrenal function gave rise to the expected changes in the composition and amounts of excreted diolones (Figs. 3 and 4).

Cortisol secretion rates. Cortisol secretion rates of five subjects were determined by the present method by using paper chromatography for the separation and the Zimmermann reaction for the measurement of 11-oxoaetiocholanolone, 11 $\beta$-hydroxyaetiocholanolone and $11 \beta$-hydroxyandrosterone derived from the urinary glucosiduronic acids of tetrahydrocortisone, tetrahydrocortisol and allotetrahydrocortisol respectively. G.l.c. showed each

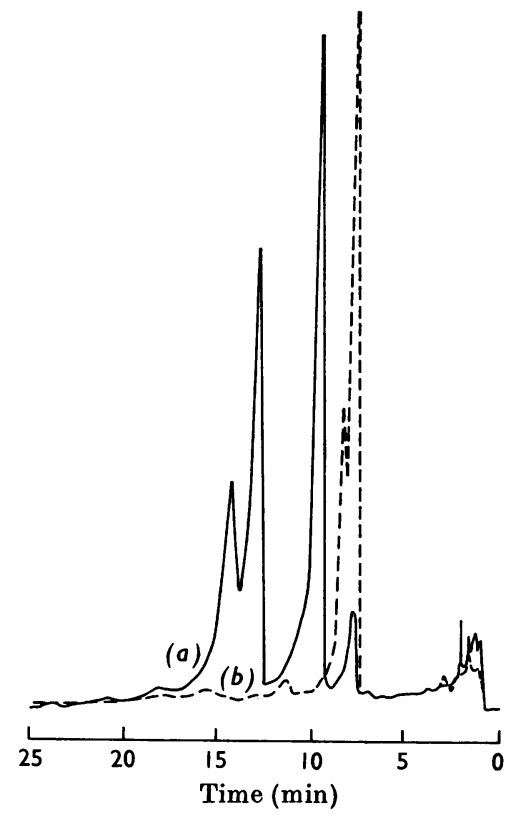

Fig. 3. G.l.c. as in Fig. 2. (a) Sample corresponding to $0.05 \mathrm{ml}$ of urine from a patient with Cushing's syndrome; attenuation $10 \times 4 ;(b)$ sample corresponding to $0.1 \mathrm{ml}$ of urine from a child with the hypertensive form of adrenogenital syndrome; attenuation $10 \times 8$.

paper-chromatographic fraction to be homogeneous. The secretion rates were also determined by a double-isotope method based on the separation of tetrahydrocortisone and of tetrahydrocortisol + allotetrahydrocortisol and their conversion, via diacetates, into 3-monoacetates. The results are given in Table 2; mean values are shown for secretion rates calculated from the determination of tetrahydrocortisol (as 11 $\beta$-hydroxyaetiocholanolone) and of allotetrahydrocortisol (as 11 $\beta$ hydroxyandrosterone) by the present method for comparison with the corresponding results obtained by the double-isotope method.

\section{DISCUSSION}

The application of the proposed method to any analytical sample should lead to the separation of a fraction containing only ketones and aldehydes derived from dihydroxyacetones. It has been shown that such fractions from human urine contained 17-oxoandrostanes (derived from steroidal dihydroxyacetones) as the only constituents detectable by g.l.c. with the exception of traces of impurities introduced during analysis and of some very volatile components. It is possible that the 
latter were not of urinary origin since similar early peaks were occasionally seen on g.l.c. tracings of pure compounds. When glucosiduronic acids of pregnane-17,21-diol-20-ones were determined it was not practicable to remove other acids before the sequential oxidation and it is possible that some of

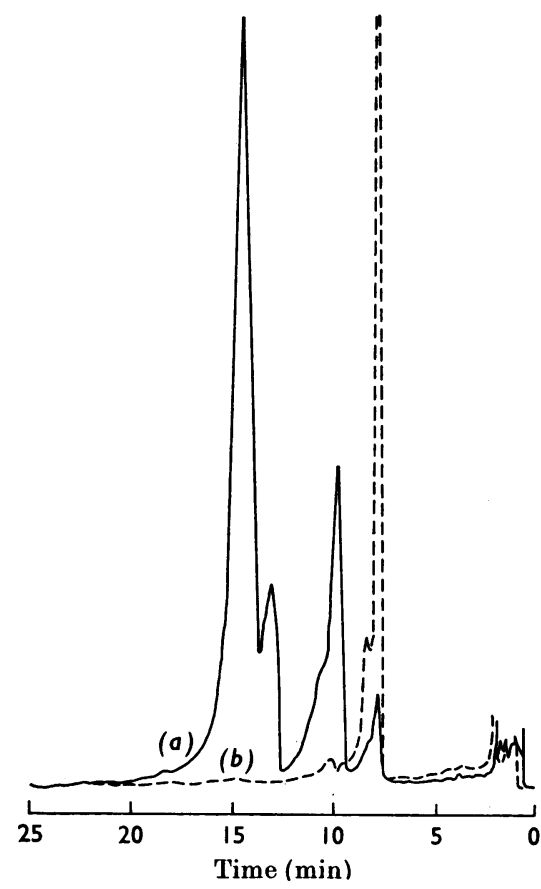

Fig. 4. G.l.c. as in Fig. 2. (a) Sample corresponding to $0.05 \mathrm{ml}$ of urine from a healthy woman treated with adrenocorticotrophin; attenuation $10 \times 8$; (b) sample corresponding to $0.1 \mathrm{ml}$ of urine from a healthy woman treated with Metopyrone; attenuation $10 \times 8$. the isolated 17-ones were derived from 17-hydroxyaetianic acids. The contribution of these precursors is unlikely to be large as it is known that man converts cortisol predominantly into conjugates of neutral metabolites (Fukushima, Bradlow, Hellman, Zumoff \& Gallagher, 1960).

Although the present work was limited to the detection of urinary 17,21-diol-20-ones and the determination of the secretion rate of cortisol, the intrinsic specificity and relative simplicity of the method suggest a wider scope of application. One possible application is the group determination of urinary diolones by the measurement of the formed 17-oxo steroids as Zimmermann chromogens. Because of the virtual absence of impurities the assay should be very reliable; it does not account for 21-deoxycorticosteroids (e.g. pregnanetriol) and the results should be relatively easy to interpret. Moreover, a small portion of the unresolved mixture of 17-ones could be retained and, when necessary, chromatographed to obtain unequivocal information about the composition of urinary 17,21-diol-20-ones. It seems worth while to consider the replacement of the routine determination of urinary 17-hydroxy corticosteroids (Appleby, Gibson, Norymberski \& Stubbs, 1955; Few, 1961) by the proposed assay.

A more general conclusion to be drawn from our results is that they lend support to the validity of the general analytical approach referred to in the introduction. Thus they show that, by chemical means alone, it is possible to process a complex mixture in such a manner that a preselected group of compounds is transformed into products separable from the original components of the mixture and resolvable into individual compounds each of which derives from a single precursor.

We are indebted to Professor Kitty Ponse for the facilities made available to us at the Institute d'Endocrinologie,

\section{Table 2. Cortisol secretion rates}

Values in italics were obtained by the double-isotope method, all others by the present method.

Cortisol secretion rate $(\mathrm{mg} / 24)$ based on the determination of

$\begin{array}{ccccc}\text { Subject } & \text { Tetrahydrocortisone } & \text { Tetrahydrocortisol } & \text { Allotetrahydrocortisol } & \begin{array}{c}\text { Tetrahydrocortisol } \\ \text { +allotetrahydrocortisol }\end{array} \\ 1 & 14.2 & 16.0 & 16.8 & 16.4 \\ 2 & 13.4 & 18.5 & & 16.5 \\ 3 & 24.1 & 15.3 & 21.7 & 20.1 \\ & 22.3 & & 13.1 & 24.2 \\ 4 & 10.2 & 14.2 & 12.4 & 11.9 \\ & 9.1 & 18.6 & 20.8 & 13.3 \\ 5 & 11.5 & & & 12.2 \\ & 10.0 & & & 19.7\end{array}$


Geneva, where some of the preliminary experiments were carried out, to Dr C. J. W. Brooks and Mr B. S. Middleditch for the g.l.c.-mass-spectroscopic analyses, to Miss Maureen Manson for help with the g.l.c. characterization of unsaturated ketones, and to Hoffmann-La Roche, Basle, Switzerland, and Fondation Montus for financial support.

\section{REFERENCES}

Appleby, J. I., Gibson, G., Norymberski, J. K. \& Stubbs, R. D. (1955). Biochem.J.60, 453.
Brooks, C. J. W. \& Norymberski, J. K. (1953). Biochem.J. $55,371$.

Bush, I. E. (1961). The Chromalography of Steroids, p. 358. London: Pergamon Press Ltd.

Chamberlain, J. \& Thomas, G. H. (1963). Biochem. J. 86, 3 P.

Few, J. D. (1961). J. Endocr. 22, 31.

Fukushima, D., Bradlow, H. L., Hellman, L., Zumoff, B. \& Gallagher, T. F. (1960). J. biol. Chem. 235, 2246.

Norymberski, J. K. (1966). Proc. 2nd int. Cong. Steroidal Hormones, Milan, p. 16. 